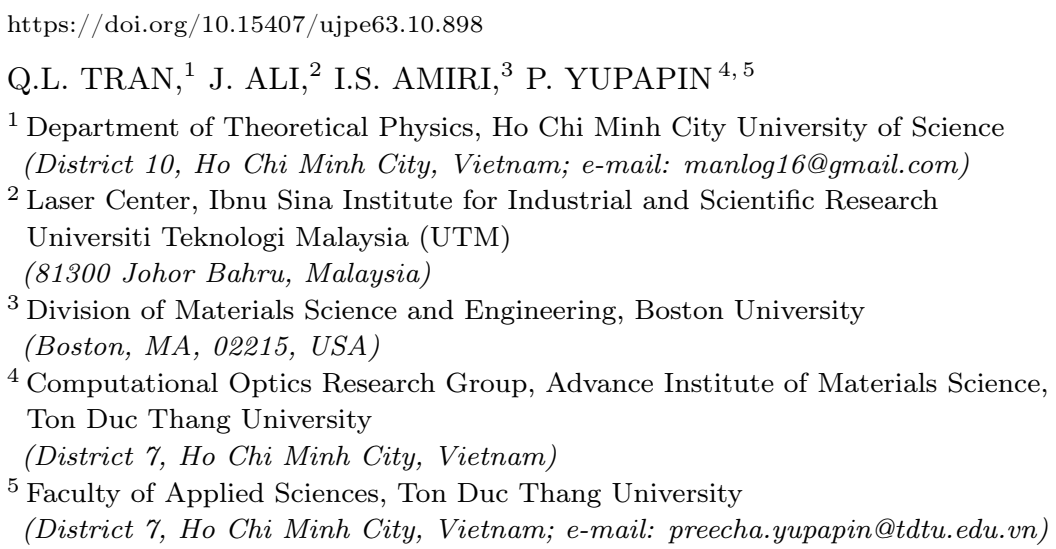

\title{
SIMULATION RESULTS OF COHERENT LIGHT IN A MODIFIED MICRORING RESONATOR
}

\section{Introduction}

Optical microring resonators are promising devices and investigated both theoretically and experimentally [1-4]. One of them is an add-drop filter, which is found very useful in many applications [5-8]. The nonlinear microring resonator (MRR) is more important in small-scale devices and has gained interest in many areas of researches and investigations [911] such as the optical nonlinear switching, modulators, all-optical signal processing, biochemical sensing, etc. Generally, the input source of a system characterized by appropriate parameters of a waveguide material and dimensions can be a Gaussian light, polarized light, or soliton pulses. Therefore, the mathematical modeling to accommodate the propagation can be suitably selected, where most of the problems are finally numerically solved, and the results are in-

(C) Q.L. TRAN, J. ALI, I.S. AMIRI, P. YUPAPIN, 2018

\section{8}

terpreted. Mathematically, various methods that can be applied to describe the light propagation within a microring resonator are available. They are (i) the graphical Meson's rule to define a transfer function for the propagating light [12-14], wave equation and ray tracing methods, and (ii) the nonlinear Schrodinger equation and the Dirac method are suitable, when the quantum nature of light is considered $[15,16]$. The output signals are claimed to be the photon distribution, which can be detected and found by the photon counter (photomultiplier). To describe the quantum picture, the propagation of waves is considered to have the wave-particle duality aspects. The wave packet must satisfy the Schrödinger equation, and the slowly varying amplitude is bound within the system realistically fabricated in the microscale dimensions, from which the photon outputs can be detected at the center rings or the output device ports. The detailed mathematical formulation of photons in a mi-

ISSN 2071-0194. Ukr. J. Phys. 2018. Vol. 63, No. 10 


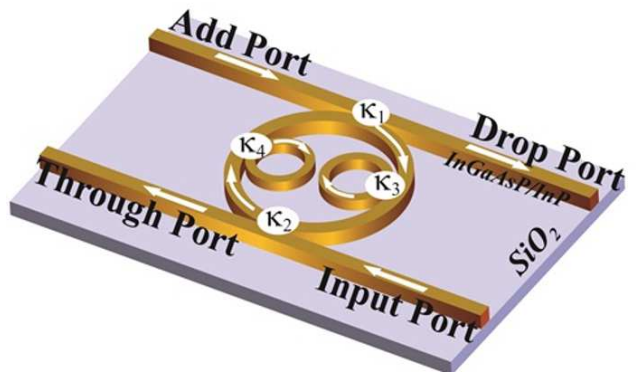

$a$

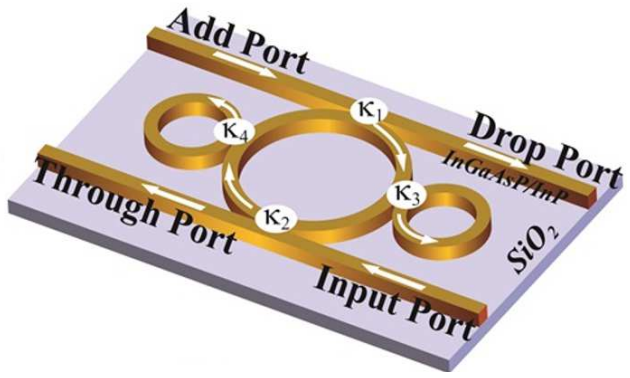

$b$

Fig. 1. A nonlinear ring resonator system with the internal (a) and external phase modulators (b)

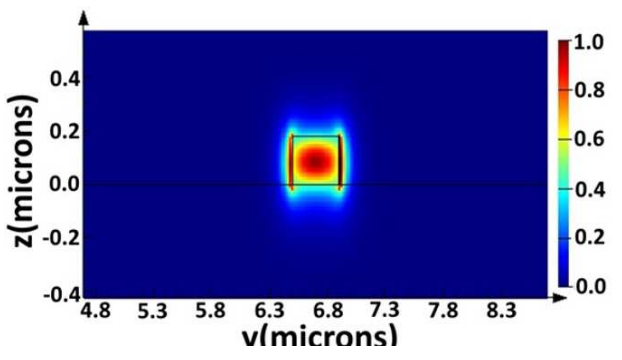

$a$

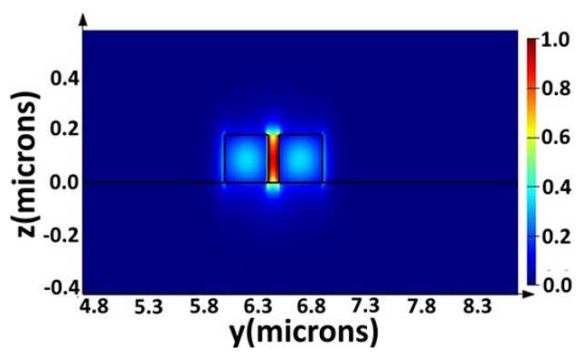

$b$

Fig. 2. Mode 1 for the Modal $E$ field at $1.55 \mu \mathrm{m}$, where the Q factor of $1.55 \mathrm{~mm} \simeq 2000, \kappa_{1} \simeq 0.41$ $(a)$, the coupling area $(b)$

croring resonator can reveal the extent of potential applications of microring resonators. In this paper, we investigate the output signals of a Panda nonlinear ring resonator, by applying the wave equation. We separate the light into its $p$ and $s$ polarized components and assume that the wave-packet meets the wave-particle duality. However, whenever the particle is projected and measured, the final picture becomes a classical view.

\section{Model}

The optical add-drop filter based on a microring resonator has the dimension of a few microns, which is a passive device with the filtering and multiplexing functions. When the phase modulator is added by a nonlinear ring resonator, some interesting aspects and potential applications occur [17-19]. The large light pulse width is become smaller that can get the faster switching time and is useful for the high-speed transmission, while the narrower line width offers a higher interferometric resolution. By using the appropriate two side ring radii, the WGM output can be obtained, which offers many potential applications. The sensing applications using the two side rings are also avail- able. By definition,

$\mathrm{FSR}=\Delta \lambda=\frac{\lambda^{2}}{n_{g} L}$,
$Q=\frac{\lambda}{\delta \lambda}=\frac{n_{g} L \pi}{\lambda} \frac{\sqrt{1-\left|\kappa_{1}\right|^{2}}}{\left|\kappa_{1}\right|^{2}}$.

Principally, the separation between two consecutive resonant peaks at the drop port is known as the free spectral range (FSR). To enhance the MRR systems, the FSR must be selected carefully. The wider FSR exhibits a better performance of the MRR. The desired FSR and quality factor (Q-factor) for a silicon insulator (SOI) underlie the waveguide design targeting on-chip communication applications. There are four different device configurations of a nonlinear $\mathrm{MRR}$, in which two phase modulators are incorporated, and a mathematical formulation for the waveparticle duality can be employed. These systems are graphically illustrated in Figs. 1 and 2. By using the graphical method called the Optiwave program, the preliminary result is obtained before the numerical method being applied. In the proposed system, we use the Eigenmode Solver on a 3D waveguide cross section to calculate the group index from $1.5 \mu \mathrm{m}$ to 
1.6 $\mu \mathrm{m}$. The desired FSR of $13.3 \mathrm{~nm}$ at the wavelength of $1.55 \mu \mathrm{m}$ is employed. By using a combination of the Lumerical FDTD Solutions (for 3D FDTD simulation) and Lumerical MODE Solutions (for 2.5D varFDTD simulation), the PANDA system is formed on an SOI waveguide. The central input wavelength is ranged from $1.50 \mu \mathrm{m}$ to $1.60 \mu \mathrm{m}$, by using the Finite Difference Eigenmode expansion for the desired FSR of $13.3 \mathrm{~nm}$, which is at a wavelength of $1.55 \mu \mathrm{m}$. The master ring radius is $6.2 \mu \mathrm{m}$. Two outer side rings are $3.1 \mu \mathrm{m}$ in size. The waveguide has the thickness of $0.4 \mu \mathrm{m} \times 0.18 \mu \mathrm{m}$ and a $0.1-\mu \mathrm{m}$ gap between each other.

\section{Analytical}

The 3D FDTD method is a rigorous method for computational electromagnetics, its versatility is the accuracy, near linear scaling, excellence for the field visualization, ability of a broad frequency response in one simulation, excellence for volumetrically complex devices, incorporation of the nonlinear behavior, and well understood error mechanisms. Starting with the 3D Maxwell equation in in a time-domain for the perfectly matched layer, the propagation of the TE and TM modes, which can be considered to be the wave packet for the particle-wave duality presentation, can be described by the following equations [20]:

$$
\begin{aligned}
& \frac{\partial}{\partial t} H_{x}(t)+\frac{\sigma_{y}^{\prime}+\sigma_{z}^{\prime}}{\varepsilon_{0}} H_{x}(t)+\frac{\sigma_{y}^{\prime} \sigma_{z}^{\prime}}{\varepsilon_{0}^{z}} \int_{-\infty}^{t} H_{x}(\tau) d \tau= \\
& =\frac{c_{0}}{\mu_{x x}}\left(\frac{\partial \tilde{E}_{z}(t)}{\partial y}-\frac{\partial \tilde{E}_{y}(t)}{\partial z}\right)-\frac{c_{0} \sigma_{x}^{\prime}}{\varepsilon_{0} \mu_{x x}} \times \\
& \times \int_{-\infty}^{t}\left(\frac{\partial \tilde{E}_{z}(t)}{\partial y}-\frac{\partial \tilde{E}_{y}(t)}{\partial z}\right) d \tau, \\
& \frac{\partial}{\partial t} H_{y}(t)+\frac{\sigma_{x}^{\prime}+\sigma_{z}^{\prime}}{\varepsilon_{0}} H_{y}(t)+\frac{\sigma_{x}^{\prime} \sigma_{z}^{\prime}}{\varepsilon_{0}^{z}} \int_{-\infty}^{t} H_{y}(\tau) d \tau= \\
& =\frac{c_{0}}{\mu_{y y}}\left(\frac{\partial \tilde{E}_{x}(t)}{\partial z}-\frac{\partial \tilde{E}_{z}(t)}{\partial x}\right)-\frac{c_{0} \sigma_{y}^{\prime}}{\varepsilon_{0} \mu_{y y}} \times \\
& \times \int_{-\infty}^{t}\left(\frac{\partial \tilde{E}_{x}(t)}{\partial z}-\frac{\partial \tilde{E}_{z}(t)}{\partial x}\right) d \tau, \\
& \frac{\partial}{\partial t} H_{z}(t)+\frac{\sigma_{y}^{\prime}+\sigma_{z}^{\prime}}{\varepsilon_{0}} H_{z}(t)+\frac{\sigma_{x}^{\prime} \sigma_{y}^{\prime}}{\varepsilon_{0}^{z}} \int_{-\infty}^{t} H_{z}(\tau) d \tau=
\end{aligned}
$$

$=\frac{c_{0}}{\mu_{z z}}\left(\frac{\partial \tilde{E}_{y}(t)}{\partial x}-\frac{\partial \tilde{E}_{x}(t)}{\partial y}\right)-\frac{c_{0} \sigma_{z}^{\prime}}{\varepsilon_{0} \mu_{z z}} \times$

$\times \int_{-\infty}^{t}\left(\frac{\partial \tilde{E}_{y}(t)}{\partial x}-\frac{\partial \tilde{E}_{x}(t)}{\partial y}\right) d \tau$

$\frac{\partial}{\partial t} \tilde{D}_{x}(t)+\frac{\sigma_{y}^{\prime}+\sigma_{z}^{\prime}}{\varepsilon_{0}} \tilde{D}_{x}(t)+\frac{\sigma_{y}^{\prime} \sigma_{z}^{\prime}}{\varepsilon_{0}^{z}} \int_{-\infty}^{t} \tilde{D}_{x}(\tau) d \tau=$

$=\frac{c_{0}}{\mu_{x x}}\left(\frac{\partial H_{z}(t)}{\partial y}-\frac{\partial H_{y}(t)}{\partial z}\right)-\frac{c_{0} \sigma_{x}^{\prime}}{\varepsilon_{0} \mu_{x x}} \times$

$\times \int_{-\infty}^{t}\left(\frac{\partial H_{z}(t)}{\partial y}-\frac{\partial H_{y}(t)}{\partial z}\right) d \tau$

$\frac{\partial}{\partial t} \tilde{D}_{y}(t)+\frac{\sigma_{x}^{\prime}+\sigma_{z}^{\prime}}{\varepsilon_{0}} \tilde{D}_{y}(t)+\frac{\sigma_{x}^{\prime} \sigma_{z}^{\prime}}{\varepsilon_{0}^{z}} \int_{-\infty}^{t} \tilde{D}_{y}(\tau) d \tau=$

$=\frac{c_{0}}{\mu_{y y}}\left(\frac{\partial H_{x}(t)}{\partial z}-\frac{\partial H_{z}(t)}{\partial x}\right)-\frac{c_{0} \sigma_{y}^{\prime}}{\varepsilon_{0} \mu_{y y}} \times$

$\times \int_{-\infty}^{t}\left(\frac{\partial H_{x}(t)}{\partial z}-\frac{\partial H_{z}(t)}{\partial x}\right) d \tau$

$\frac{\partial}{\partial t} \tilde{D}_{z}(t)+\frac{\sigma_{y}^{\prime}+\sigma_{z}^{\prime}}{\varepsilon_{0}} \tilde{D}_{z}(t)+\frac{\sigma_{x}^{\prime} \sigma_{y}^{\prime}}{\varepsilon_{0}^{z}} \int_{-\infty}^{t} \tilde{D}_{z}(\tau) d \tau=$

$=\frac{c_{0}}{\mu_{z z}}\left(\frac{\partial H_{y}(t)}{\partial x}-\frac{\partial H_{x}(t)}{\partial y}\right)-\frac{c_{0} \sigma_{z}^{\prime}}{\varepsilon_{0} \mu_{z z}} \times$

$\times \int_{-\infty}^{t}\left(\frac{\partial H_{y}(t)}{\partial x}-\frac{\partial H_{x}(t)}{\partial y}\right) d \tau$

where

$\tilde{D}_{x}(t)=\varepsilon_{x x} \tilde{E}_{x}(t)$,

$\tilde{D}_{y}(t)=\varepsilon_{y y} \tilde{E}_{y}(t)$,

$\tilde{D}_{z}(t)=\varepsilon_{y y} \tilde{E}_{z}(t)$

$\frac{\left.H_{x}\right|_{t-\Delta t / z} ^{i j k}-\left.H_{x}\right|_{t-\Delta t / z} ^{i j k}}{\Delta t}+\frac{\left.\sigma_{y}^{H}\right|^{i j k}+\left.\sigma_{z}^{H}\right|^{i j k}}{\varepsilon_{0}} \times$

$\times\left(\frac{\left.H_{x}\right|_{t-\Delta t / z} ^{i j k}+\left.H_{x}\right|_{t-\Delta t / z} ^{i j k}}{2}\right)+\frac{\left.\left.\sigma_{y}^{H}\right|^{i j k} \sigma_{z}^{H}\right|^{i j k} \Delta t}{\varepsilon_{0}} \times$

$\times\left[\frac{1}{4}\left(\left.H_{x}\right|_{t+\Delta t / 2} ^{i j k}+\left.H_{x}\right|^{i j k}\right)+\left.\sum_{T=\Delta t / 2}^{t-\Delta t / 2} H_{x}\right|_{T} ^{i j k}\right]=$

$=-\left.\frac{C_{0}}{\left.\mu_{x x}\right|^{i j k}} C_{x}^{E}\right|_{t} ^{i j k}-\left.\frac{\left.c_{0} \Delta t \sigma_{x}^{H}\right|^{i j k}}{\left.\varepsilon_{0} \mu_{x x}\right|^{i j k}} \sum_{T=0}^{t} C_{x}^{E}\right|_{T} ^{i j k}$,

ISSN 2071-0194. Ukr. J. Phys. 2018. Vol. 63, No. 10 


$$
\begin{aligned}
& \frac{\left.H_{y}\right|_{t+\Delta t / z} ^{i j k}-\left.H_{y}\right|_{t-\Delta t / z} ^{i j k}}{\Delta t}+\frac{\left.\sigma_{x}^{H}\right|^{i j k}+\left.\sigma_{z}^{H}\right|^{i j k}}{\varepsilon_{0}} \times \\
& \times\left(\frac{\left.H_{y}\right|_{t+\Delta t / z} ^{i j k}+\left.H_{y}\right|_{t-\Delta t / z} ^{i j k}}{2}\right)+\frac{\left.\left.\sigma_{y}^{H}\right|^{i j k} \sigma_{z}^{H}\right|^{i j k} \Delta t}{\varepsilon_{0}} \times \\
& \times\left[\frac{1}{4}\left(\left.H_{y}\right|_{t+\Delta t / 2} ^{i j k}+\left.H_{y}\right|_{t-\Delta t / 2} ^{i j k}\right)+\left.\sum_{T=\Delta t / 2}^{t-\Delta t / 2} H_{y}\right|_{T} ^{i j k}\right]= \\
& =-\left.\frac{C_{0}}{\mu_{y y} \mid{ }^{i j k}} C_{y}^{E}\right|_{t} ^{i j k}-\left.\frac{\left.c_{0} \Delta t \sigma_{z}^{H}\right|^{i j k}}{\left.\varepsilon_{0} \mu_{x x}\right|^{i j k}} \sum_{T=0}^{t} C_{x}^{E}\right|_{T} ^{i j k}, \\
& \frac{\left.H_{z}\right|_{t+\Delta t / z} ^{i j k}-\left.H_{z}\right|_{t-\Delta t / z} ^{i j k}}{\Delta t}+\frac{\left.\sigma_{x}^{H}\right|^{i j k}+\left.\sigma_{y}^{H}\right|^{i j k}}{\varepsilon_{0}} \times \\
& \times\left(\frac{\left.H_{z}\right|_{t+\Delta t / z} ^{i j k}+\left.H_{z}\right|_{t-\Delta t / z} ^{i j k}}{2}\right)+\frac{\left.\left.\sigma_{x}^{H}\right|^{i j k} \sigma_{y}^{H}\right|^{i j k} \Delta t}{\varepsilon_{0}} \times \\
& \times\left[\frac{1}{4}\left(\left.H_{z}\right|_{t+\Delta t / 2} ^{i j k}+\left.H_{z}\right|_{t-\Delta t / 2} ^{i j k}\right)+\left.\sum_{T=\Delta t / 2}^{t-\Delta t / 2} H_{z}\right|_{T} ^{i j k}\right]= \\
& =-\left.\frac{C_{0}}{\left.\mu_{z z}\right|^{i j k}} C_{z}^{E}\right|_{t} ^{i j k}-\left.\frac{\left.c_{0} \Delta t \sigma_{z}^{H}\right|^{i j k}}{\left.\varepsilon_{0} \mu_{z z}\right|^{i j k}} \sum_{T=0}^{t} C_{z}^{E}\right|_{T} ^{i j k}, \\
& \frac{\left.\tilde{D}_{x}\right|_{t+\Delta t / z} ^{i j k}-\left.\tilde{D}_{x}\right|_{t} ^{i j k}}{\Delta t}+\frac{\left.\sigma_{y}^{D}\right|^{i j k}+\left.\sigma_{z}^{D}\right|^{i j k}}{\varepsilon_{0}} \times \\
& \times\left(\frac{\left.\tilde{D}_{x}\right|_{t+\Delta t} ^{i j k}+\left.\tilde{D}_{x}\right|_{t} ^{i j k}}{2}\right)+\frac{\left.\left.\sigma_{y}^{D}\right|^{i j k} \sigma_{z}^{D}\right|^{i j k} \Delta t}{\varepsilon} \times \\
& \times\left[\frac{1}{4}\left(\left.\tilde{D}_{x}\right|_{t+\Delta t / 2} ^{i j k}+\left.\tilde{D}_{x}\right|_{t} ^{i j k}\right)+\left.\sum_{T=\Delta t / 2}^{t-\Delta t / 2} \tilde{D}_{x}\right|_{T} ^{i j k}\right]= \\
& =\left.c_{0} C_{x}^{H}\right|_{t} ^{i j k}+\left.\frac{\left.c_{0} \Delta t \sigma_{x}^{D}\right|^{i j k}}{\varepsilon_{0}} \sum_{T=\Delta t / 2}^{t-\Delta t / 2} C_{x}^{H}\right|_{T} ^{i j k}, \\
& \frac{\left.\tilde{D}_{y}\right|_{t+\Delta t} ^{i j k}-\left.\tilde{D}_{y}\right|_{t} ^{i j k}}{\Delta t}+\frac{\left.\sigma_{x}^{D}\right|^{i j k}+\left.\sigma_{z}^{D}\right|^{i j k}}{\varepsilon_{0}} \times \\
& \times\left(\frac{\left.\tilde{D}_{y}\right|_{t+\Delta t} ^{i j k}+\left.\tilde{D}_{y}\right|_{t} ^{i j k}}{2}\right)+\frac{\left.\left.\sigma_{x}^{D}\right|^{i j k} \sigma_{z}^{D}\right|^{i j k} \Delta t}{\varepsilon_{0}} \times \\
& \times\left[\frac{1}{4}\left(\left.\tilde{D}_{y}\right|_{t+\Delta t} ^{i j k}+\left.\tilde{D}_{y}\right|_{t} ^{i j k}\right)+\left.\sum_{T=\Delta t / 2}^{t-\Delta t / 2} \tilde{D}_{y}\right|_{T} ^{i j k}\right]= \\
& =\left.c_{0} C_{y}^{H}\right|_{t} ^{i j k}+\left.\frac{\left.c_{0} \Delta t \sigma_{y}^{D}\right|^{i j k}}{\varepsilon_{0}} \sum_{T=\Delta t / 2}^{t-\Delta t / 2} C_{y}^{H}\right|_{T} ^{i j k}, \\
& \frac{\left.\tilde{D}_{z}\right|_{t+\Delta t / z} ^{i j k}-\left.\tilde{D}_{z}\right|_{t} ^{i j k}}{\Delta t}+\frac{\left.\sigma_{x}^{D}\right|^{i j k}+\left.\sigma_{y}^{D}\right|^{i j k}}{\varepsilon_{0}} \times \\
& \times\left(\frac{\left.\tilde{D}_{z}\right|_{t+\Delta t / z} ^{i j k}+\left.\tilde{D}_{z}\right|_{t} ^{i j k}}{2}\right)+\frac{\left.\left.\sigma_{x}^{D}\right|^{i j k} \sigma_{y}^{D}\right|^{i j k} \Delta t}{\varepsilon_{0}} \times
\end{aligned}
$$

ISSN 2071-0194. Ukr. J. Phys. 2018. Vol. 63, No. 10

$$
\begin{aligned}
& \times\left[\frac{1}{4}\left(\left.\tilde{D}_{z}\right|_{t+\Delta t} ^{i j k}+\left.\tilde{D}_{z}\right|_{t} ^{i j k}\right)+\left.\sum_{T=0}^{t} \tilde{D}_{z}\right|_{T} ^{i j k}\right]= \\
& =\left.c_{0} C_{z}^{H}\right|_{t} ^{i j k}+\left.\frac{\left.c_{0} \Delta t \sigma_{z}^{D}\right|^{i j k}}{\varepsilon_{0}} \sum_{T=\Delta t / 2}^{t-\Delta t / 2} C_{z}^{H}\right|_{T} ^{i j k}, \\
& \left.\tilde{D}_{x}\right|_{t+\Delta t} ^{i j k}=\left.\left.\epsilon_{x x}\right|^{i j k} \tilde{E}_{x}\right|_{t+\Delta t} ^{i j k}, \\
& \left.\tilde{D}_{y}\right|_{t+\Delta t} ^{i j k}=\left.\left.\epsilon_{y y}\right|^{i j k} \tilde{E}_{y}\right|_{t+\Delta t} ^{i j k}, \\
& \left.\tilde{D}_{z}\right|_{t+\Delta t} ^{i j k}=\left.\left.\epsilon_{z z}\right|^{i j k} \tilde{E}_{z}\right|_{t+\Delta t} ^{i j k},
\end{aligned}
$$

where $E_{i}(V / m)$ are components of the electric field, $\tilde{E}_{i}=\sqrt{\frac{\varepsilon_{0}}{\mu_{0}}} E_{i}$ are components of the normalized electric field, $\tilde{D}_{i}$ are components of the normalized electric displacement field, $\sigma_{i}(S / m)$ are components of the electric conductivity, $\varepsilon_{i} j(F / m)$ are tensor components of the permittivity, $\mu_{i} j(H / m)$ are tensor components of the permeability, $c_{0}(\mathrm{~m} / \mathrm{s})$ is the speed of light in vacuum.

With refard for the preliminary data, the results are plotted in Figs. 3 and 4 . The biggest drawback of $3 \mathrm{D}$ FDTD is the highly intense computation, making it difficult to efficiently treat large integrated optical components. The 2.5D FDTD method collapses a $3 \mathrm{D}$ geometry into a $2 \mathrm{D}$ set of the effective indices, in which the propagation of light within the slab waveguide is solved, by using 2D FDTD. The first step is to identify the vertical slab modes of the core waveguide structure. Then we mesh the structure and collapse the $3 \mathrm{D}$ material into effective $2 \mathrm{D}$ indices, where the dispersion comes from the original material properties and the slab waveguide geometry. The 2.5D FDTD provides the simulation speed over 10 times faster, which provides the results comparable to $3 \mathrm{D}$ FDTD in the case of a simple MRR. The $2.5 \mathrm{D}$ varFDTD

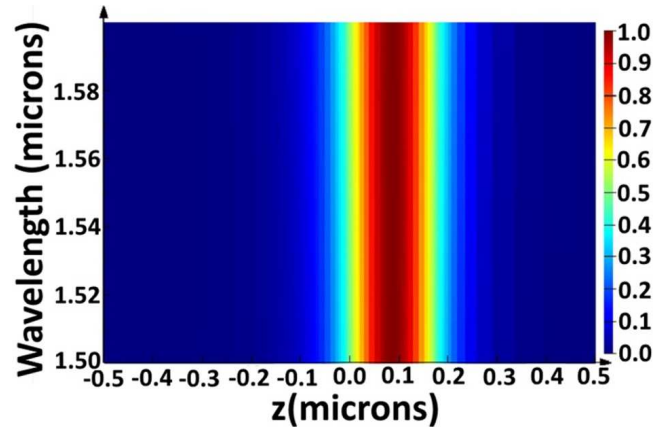

Fig. 3. Illustration of the waveguide dispersion in the $z$ direction vertical slab mode with the use of the $2.5 \mathrm{D}$ varFDTD 

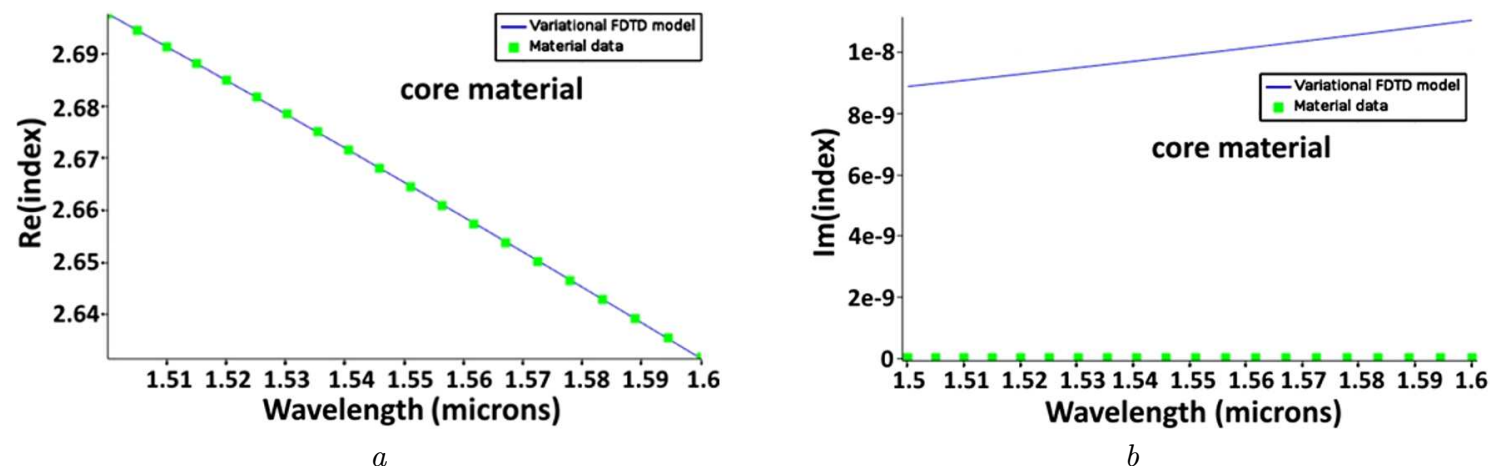

Fig. 4. The effective dispersive index with real $(a)$ and imaginary $(b)$ parts, where the generated dispersion of materials comprises the original properties of silicon and the waveguide dispersion determined by the slab waveguide geometry [25]

results in the $2.7 \%$ group index error in FSR as compared with 3D FDTD, using only the simulation time and memory of a 2D FDTD simulation. This is the specific user for optimizing the design, since a designer has to iterate the simulation through many design parameters, as well as the ability to simulate large complex components [22-24].

The refractive index can be calculated by

$\varepsilon_{\mathrm{eff}}^{\mathrm{TE}}(x, y, z)=\left(\frac{B_{r}}{k}\right)^{2}+$
$+\frac{\int_{z}\left[\varepsilon(x, y, z)-\varepsilon_{r}(z, \varpi)\right]|M(x, \varpi)|^{2} d z}{\int_{z}|M(x, \varpi)|^{2} d z}$

for the traverse electric mode and

$$
\begin{aligned}
& \varepsilon_{\mathrm{eff}}^{\mathrm{TM}}(x, y, z)=\left(\frac{B_{r}}{k}\right)^{2} \frac{\int_{z} \frac{1}{\varepsilon_{r}}|M|^{2} d z}{\int_{z} \frac{1}{\varepsilon(x, y, z)}|M|^{2} d z}+ \\
& +\frac{\int_{z} \frac{1}{\varepsilon_{r}}\left(\frac{1}{\varepsilon_{r}}-\frac{1}{\varepsilon(x, y, z)}\right)\left|\frac{\partial M}{\partial z}\right|^{2} d z}{k^{2} \int_{z} \frac{1}{\varepsilon(x, y, z)}|M|^{2} d z}
\end{aligned}
$$

for the traverse magnetic mode.

\section{Numerical Results}

The phase modulator is introduced and integrated with the add-drop filter, which introduces a nonlinear effect into the center ring material. By controlling the suitable input power and device material parameters, the output in various forms such as a soliton, chaos, whispering gallery mode, polarized light, and photons can be obtained. In this work, the input light propagates in the $z$ direction, where there are two composed fields, which are the traverse electric and magnetic fields (TE and TM). We start from the mode propagation equation, where the superposition between modes under the specific condition leads to the generation of various forms of the output. In a simulation, the 2.5D FDTD method gives the following electric field output signals at the drop and through ports, where we can see the resonant reflection and transmission occurring at $S 11$ - Input port. The powers reflected and leaking out $S 41$ - Control (Add) port are equivalent. The results are plotted in Figs. 5-7. These are due to a weak coupling between the forward and backward propagating modes in the ring, which can have a substantial effect due to the high Q-factor of the device. The FSRs for two methods are nearly the same, but we can see the standing wave pattern from the forward and backward propagating modes, which leads to the Rabi splitting observed at the Though port. This is also an advantage of 3D FDTD over 2.5D varFDTD to show that the backscattering effects can have important consequences in real devices. All the plots use the vertical $y$-axis as dimensionless, while the $x$-axis uses the wavelength and frequency units.

The $E$-fields are derived from the $2.5 \mathrm{D}$ FDTD model applied to the $x$-plane and $y$-plane. The complex components of the reflection and transmission coefficients can be described by $2 \times 2$ transmission lines, which is given by [26]

$$
\left(\begin{array}{l}
b 1 \\
b 2
\end{array}\right)=\left(\begin{array}{ll}
S 11 & S 12 \\
S 21 & S 22
\end{array}\right)\left(\begin{array}{l}
a 1 \\
a 2
\end{array}\right),
$$



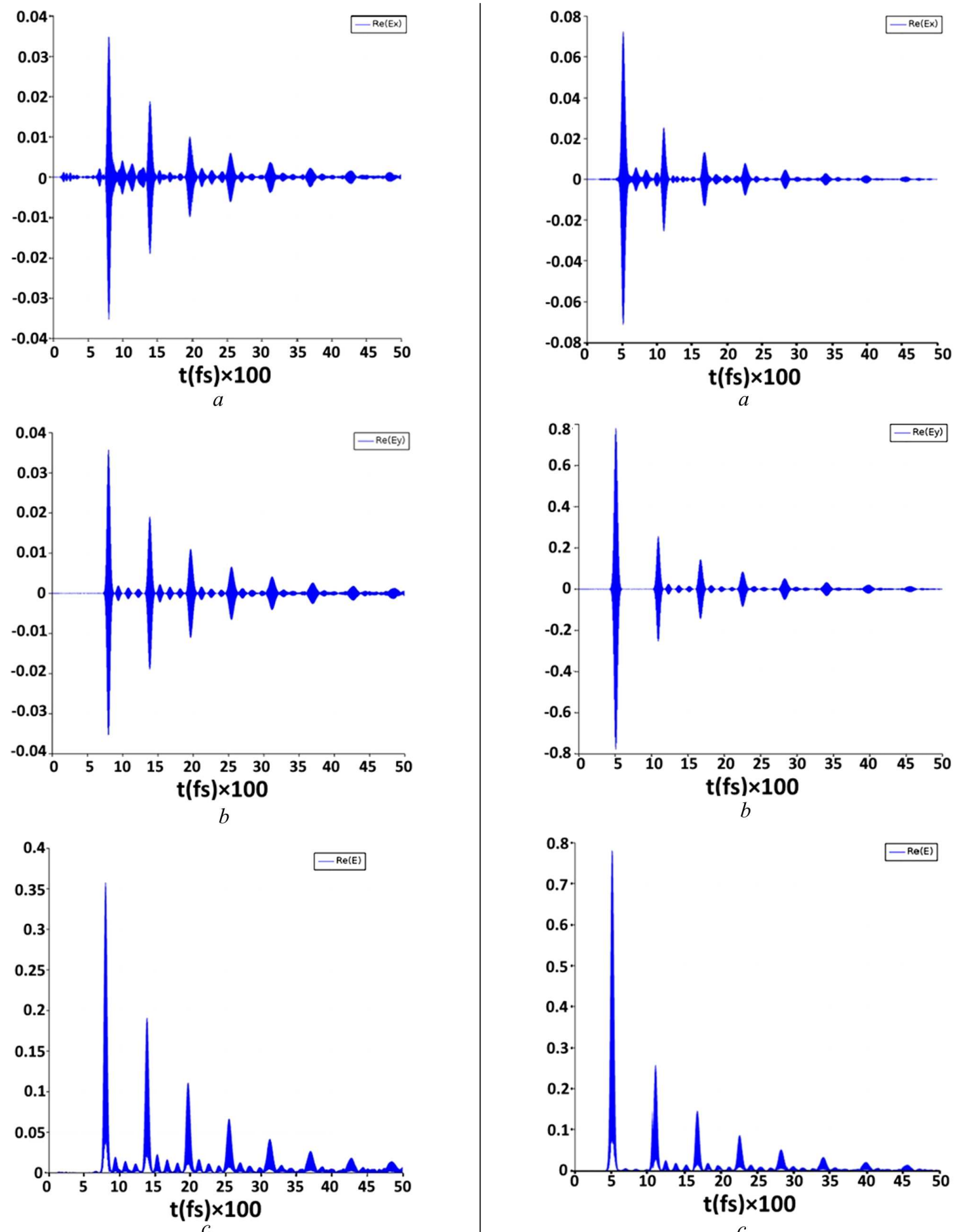

Fig. 5. Plots of electric field outputs at the Drop Port for the real $E_{x}(a)$, real $E_{y}(b)$, and real $E(c)$

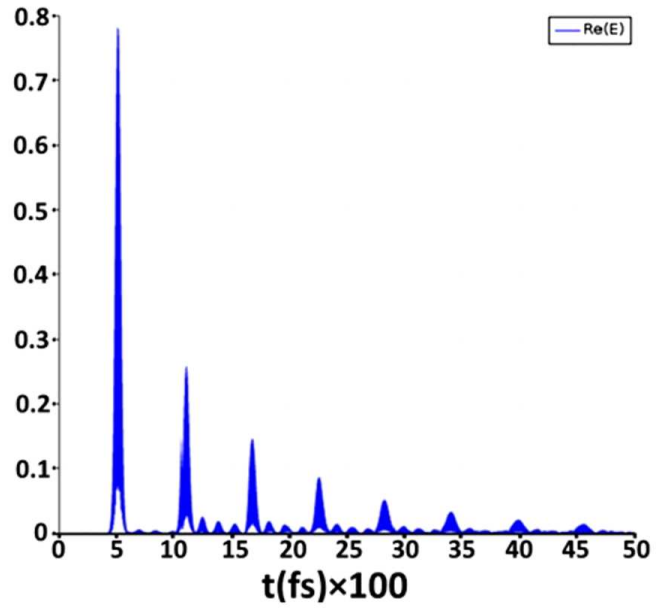
$c$

Fig. 6. Plots of the electric field outputs at the Through Port for the real $E_{x}(a)$, real $E_{y}(b)$, and real $E(c)$ 


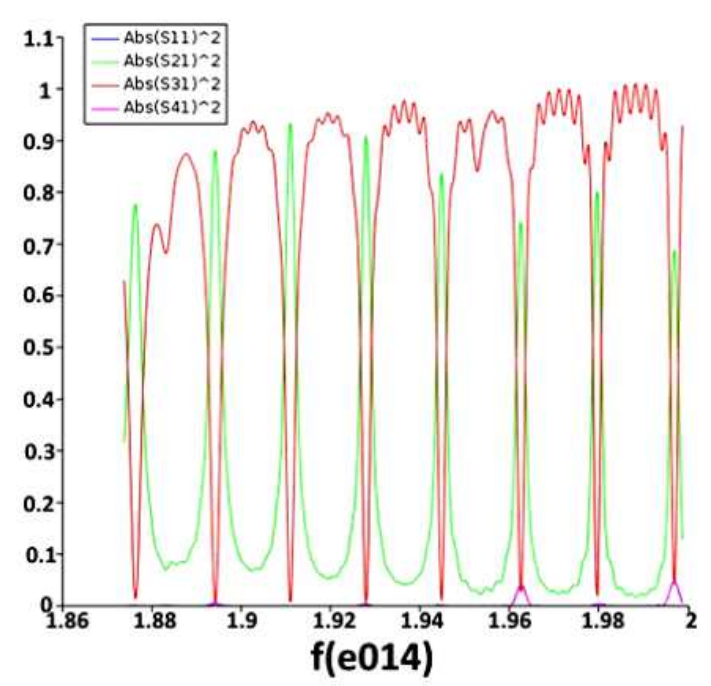

$a$

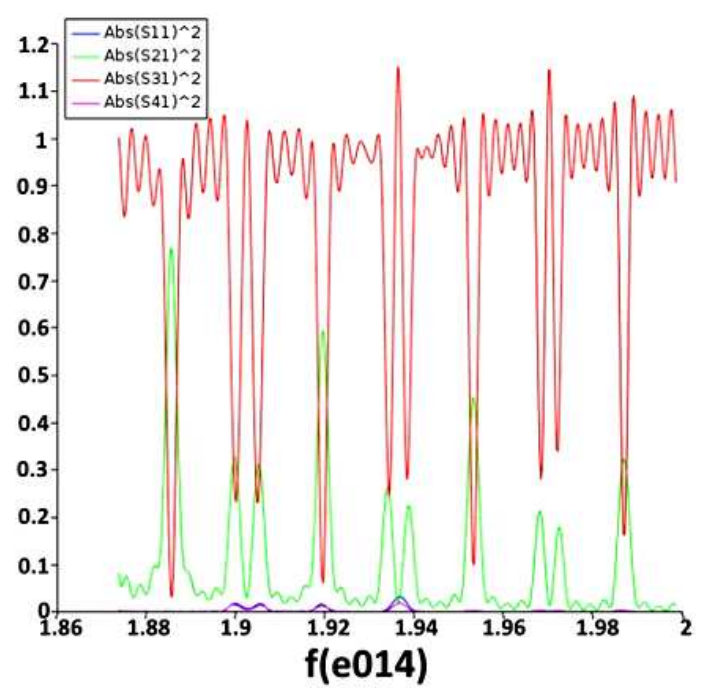

$b$

Fig. 7. Plots of the $S$-parameter extraction of the $S 21$ - Drop Port and $S 31$ - Though Port, by using $2.5 \mathrm{D}$ varFDTD (a) and 3D FDTD $(b)$. The entangled photons between the through and drop ports are seen

where $S 11$ and $S 21$ are $E_{\text {reflect }} / E_{\text {incident }}$ and $E_{\text {transmit }} / E_{\text {incident }}$, respectively. With the assumption that the structure does not significantly affect the polarization of the incident fields, and that the fields are polarized along one of the major axes. We note also that the transmitted and reflected fields must propagate like a simple plane wave at the point of measurement, and the sources and monitors are always at some distance from the surface of the metamaterial to avoid evanescent fields. By using two different methods, the results of photon outputs at the Drop and Through ports are obtained and plotted.

\section{Conclusion}

We have presented the analytical and numerical results for the light traveling within a Panda ring resonator, where two side rings are the phase modulators, which induces a nonlinear effect into the center ring. The numerical results have shown that the quantum picture can be obtained, which is confirmed by the output photon entanglement. The photon oscillation (switching) time can be increased by the phase modulator. The quantum picture of the result is very interesting, when the outputs of the required ports are detected. This can be used for the quantum aspect interpretation, which offers the use of the proposed device in applications such as quantum cryptography, a quantum interferometer, quantum sen- sor, quantum communication, quantum computing devices, and the signal processing. The further investigations of, for instance, the WGM, microring antenna, chaotic circuit, and microsensing applications are of significant interest.

The authors would like to give acknowledgement to the Ton Duc Thang University, Ho Chi Minh City, Vietnam for the research facilities, Tier1 grant (16H44), and UTM Shine Kumpulan III program of the Technology University of Malaysia.

1. I.S. Amiri, J. Ali, P.P. Yupapin. Enhancement of FSR and finesse using add/drop filter and PANDA ring resonator systems. Int. J. Mod. Phys. B 26, 1250034 (2012).

2. J.-T. Shen, S. Fan. Theory of single-photon transport in a single-mode waveguide. I. Coupling to a cavity containing a two-level atom. Phys. Rev. A 79, 023838 (2009).

3. W. Bogaerts, P.D. Heyn, T.V. Vaerenbergh, K.D. Vos, S.K. Selvaraja, T. Claes, P. Dumon, P. Bienstman, D.V. Thourhout, R. Baets. Silicon microring resonator. Laser Photon. Rev. 6, 47 (2011).

4. A.S. Prabhu, A. Tsay, Z. Han, V. Van. Extreme miniaturization of silicon add-drop microring filters for VLSI photonics applications. IEEE Photon. J 2, 436 (2010).

5. P. Zhou, L. Zhang, Y. Tian, L. Yang. $10 \mathrm{GHz}$ electrooptical OR/NOR directed logic device based on silicon micro-ring resonators. Opt. Lett. 39, 1937 (2014).

6. A. Malacarne, F. Gambini, S. Faralli, J. Klamkin, L. Poti. 3D integrated hybrid silicon laser. IEEE Photon. Technol. Lett. 26, 1042 (2014).

ISSN 2071-0194. Ukr. J. Phys. 2018. Vol. 63, No. 10 
7. F. Xia, S. Sekaric, Y.A. Vlasov. Mode conversion losses in silicon-on-insulator photonic wire based racetrack resonators. Opt. Exp. 14, 3872 (2006).

8. T. Phatharaworamet, C. Teeka, R. Jomtarak, S. Mitatha, P.P. Yupapin. Random binary code generation using darkbright soliton conversion control within a Panda-ring resonator. Lightwave Technol. 28, 2804 (2013).

9. P.P. Yupapin. Generalized quantum key distribution via micro ring resonator for mobile telephone networks. Optik 121, 422 (2010).

10. I.S. Amiri, A. Afroozeh, M. Bahadoran. Simulation and analysis of multisoliton generation using a PANDA ring resonator system. Chin Phys Lett. 28, 104205 (2011).

11. K. Padmaraju, D.F. Logan, X. Zhu, J.J. Ackert, A.P. Knights, K. Bergman. Integrated thermal stabilization of a microring modulator. Opt. Exp. 21, 14342 (2013).

12. S.J. Mason. Feedback theory-some properties of signal flow graphs. Proc. IRE 44, 920 (1975).

13. P.P. Yupapin, B. Vanishkorn. Mathematical simulation of light pulse propagating within a microring resonator system and applications. Applied Math. Model. 35, 1729 (2011).

14. M. Bahadoran, J. Ali, P.P. Yupapin. Ultrafast all-optical switching using signal flow graph for PANDA resonator. Appl. Opt. 52, 2866 (2013).

15. J.W. Silverstone, R. Santaqati, D. Bonneau, M.J. Strain, M. Sorel, J.L. O'Brien, M.G. Thompson. Qubit entanglement between ring-resonator photon-pair sources on a silicon chip. Nat. Comm. 6, 7948 (2015).

16. K. Kues, C. Reimer, P. Roztocki, L.R. Cortes, S. Sciara, B. Wetzel, Y. Zhang, A. Cino, S.T. Chu, B.E. Little, D.J. Moss, L. Caspani. On-chip generation of highdimensional entangled quantum states and their coherent control. Nature 546, 622 (2017).

17. F. Sedlimeir, M.R. Foreman, U. Vogl, R. Zeltner, G. Schunk, D.V. Strekalov, C. Marquardt, G. Leuchs, H.G.L. Schwefel. On-chip multiplexed multiple entanglement sources in a single silicon nanowire. Phys. Rev. Appl. 7, 024029 (2017)

18. P. Phatharacorn, S. Chiangga, P. Yupapin. Analytical and simulation results of a triple micro whispering gallery mode probe system for a 3D blood flow rate sensor. Appl. Opt. 55, 9504 (2016).

19. W. Pongruengkiat, S. Pechprasarn. Whispering-gallery mode resonators for detecting cancer. Sensors 17, 2095 (2017).
20. Q.L. Tran, P. Yupapin. Formalism of photons in a nonlinear microring resonator. Proceeding of SPIE 10714, 107140M (2018).

21. VarFDTD, Lectures Notes, available at https://emlab.utep.edu/ee5390fdtd.htm, Accessed on 10 December, 2018.

22. Lumerical. https://kb.lumerical.com/en/solvers_varfdtd.html, Accessed on December 10, 2018.

23. Lumerical's 2.5 FDTD propagation method, https://www.lumerical.com/support/whitepaper/ 2.5d_fdtd_propagation_method.html, Accessed on December 10, 2018.

24. M. Hammer, O.V. Ivanova. Effective index approximations of photonic crystal slabs: A 2-to-1-D assessment. Optical and Quantum Electronics 41 (4), 267 (2009).

25. A.W. Snyder, J.D. Love. Optical Waveguide Theory (Chapman \& Hall, 1983).

26. D.R. Smith, D.C. Vier, Th. Koschny, C.M. Soukoulis. Electromagnetic parameter retrieval from inhomogeneous metamaterials. Phys. Rev. E 71, 036617 (2005).

Received 09.03.18

\section{К.Л. Тран, Дж. Алі, I.С. Амірі, П. Юпапін}

МОДЕЛЮВАННЯ КОГЕРЕНТНОГО СВІТЛА В МОДИФІКОВАНОМУ МІКРОКІЛЬЦЕВОМУ PE3ОНАТОРI

$\mathrm{P}$ е $з$ ю м е

Використовуючи короткі гаусові імпульси від монохроматичного джерела світла як вхідні, ми моделюємо розподіл фотонів і аналізуємо вихідні сигнали нелінійного мікрокільцевого резонатора з двома нелінійними бічними кільцями. Ця конфігурація називається Панда кільцевий резонатор, який являє собою модифікований адитивний відвідний фільтр 3 двома фазовими модуляторами. Розглянуто орієнтовані елементи зв'язку, які характеризуються двома параметрами, коефіцієнтом зв'язку за потужністю $(\kappa)$ і втратами потужності $(\gamma)$. Нелінійний показник заломлення $\left(N_{2}\right)$ фазового модулятора впливає на центральне кільце, що призводить до цікавих наслідків. Побудовано модель симуляції і представлені результати, отримані з використанням комбінації програм Lumerical FDTD і MODE. Фотони концептуально інтерпретуються як хвильові пакети. Обговорюються можливі застосування. 